J. Dairy Sci. 98:6236-6242

http://dx.doi.org/10.3168/jds.2015-9657

(C) 2015, THE AUTHORS. Published by FASS and Elsevier Inc. on behalf

of the American Dairy Science Association ${ }^{\circledR}$. This is an open access article under

the CC BY-NC-ND license (http://creativecommons.org/licenses/by-nc-nd/3.0/).

\title{
Development and validation of a novel pedometer algorithm to quantify extended characteristics of the locomotor behavior of dairy cows
}

\author{
M. Alsaaod, ${ }^{\star 1}$ J. J. Niederhauser,† G. Beer, ${ }^{*}$ N. Zehner,‡ G. Schuepbach-Regula,§ and A. Steiner* \\ ${ }^{*}$ Clinic for Ruminants, Vetsuisse-Faculty, University of Bern, 3001 Bern, Switzerland \\ †InnoClever $\mathrm{GmbH}, 4410$ Liestal, Switzerland \\ $\ddagger$ Agroscope, Institute for Sustainability Sciences, 8356 Ettenhausen, Switzerland \\ §Veterinary Public Health Institute, Vetsuisse-Faculty, University of Bern, 3001 Bern, Switzerland
}

\begin{abstract}
Behavior is one of the most important indicators for assessing cattle health and well-being. The objective of this study was to develop and validate a novel algorithm to monitor locomotor behavior of loose-housed dairy cows based on the output of the RumiWatch pedometer (ITIN+HOCH GmbH, Fütterungstechnik, Liestal, Switzerland). Data of locomotion were acquired by simultaneous pedometer measurements at a sampling rate of $10 \mathrm{~Hz}$ and video recordings for manual observation later. The study consisted of 3 independent experiments. Experiment 1 was carried out to develop and validate the algorithm for lying behavior, experiment 2 for walking and standing behavior, and experiment 3 for stride duration and stride length. The final version was validated, using the raw data, collected from cows not included in the development of the algorithm. Spearman correlation coefficients were calculated between accelerometer variables and respective data derived from the video recordings (gold standard). Dichotomous data were expressed as the proportion of correctly detected events, and the overall difference for continuous data was expressed as the relative measurement error. The proportions for correctly detected events or bouts were 1 for stand ups, lie downs, standing bouts, and lying bouts and 0.99 for walking bouts. The relative measurement error and Spearman correlation coefficient for lying time were $0.09 \%$ and 1 ; for standing time, $4.7 \%$ and 0.96 ; for walking time, $17.12 \%$ and 0.96 ; for number of strides, $6.23 \%$ and 0.98 ; for stride duration, $6.65 \%$ and 0.75 ; and for stride length, $11.92 \%$ and 0.81 , respectively. The strong to very high correlations of the variables between visual observa-
\end{abstract}

Received March 31, 2015.

Accepted May 28, 2015.

${ }^{1}$ Corresponding author: maher.alsaaod@vetsuisse.unibe.ch tion and converted pedometer data indicate that the novel RumiWatch algorithm may markedly improve automated livestock management systems for efficient health monitoring of dairy cows.

Key words: accelerometer, dairy cow, behavior, locomotion, walking

\section{INTRODUCTION}

Change of animal behavior is one of the most important criteria for assessing animal welfare and health (Cook et al., 2005; Urton et al., 2005; Chapinal et al., 2011; Viazzi et al., 2013). Parameters of animal behavior can be used to build up an early disease warning system. For example, painful claw lesions cause changes in animal behavior such as lameness (Hudson et al., 2008) and are usually associated with an increased lying time (Ito et al., 2010; Alsaaod et al., 2012; Yunta et al., 2012) and a decreased overall daily activity level (O'Callaghan et al., 2003). The current gold standard for detection of lameness is manual observation by a trained professional. The degree of lameness is described, using an accepted clinical gait-scoring scheme (Sprecher et al., 1997; Flower and Weary, 2006).

In general, veterinary treatments and management decisions are more effective the earlier they are initiated relative to the onset of the disease (Gonzalez et al., 2008). However, detecting behavioral changes at an early stage is difficult (Whay et al., 2003; Espejo et al., 2006). Traditionally, behavior research of loose-housed cows is based on direct observation or use of video recordings. The drawbacks of both methods are that they are time consuming and labor intensive with nocturnal observations, which limit their feasibility for long-term observations in practice (Muller and Schrader, 2005).

Previous studies indicated lameness to be one of the most important health and welfare problems of modern dairy farming (Nordlund et al., 2004; Shearer et al., 2013). Practical strategies to automatically detect lame- 
ness to improve claw health have, therefore, become a major focus for the dairy industry. Consequently, real-time analysis of cattle activity could provide useful information for early detection of disease, thereby reducing its negative effect, increasing the chance of treatment success, and preventing the disease from becoming chronic. Accelerometry is a reliable and useful tool to detect standing and lying behavior (Munksgaard et al., 2006; O'Driscoll et al., 2008; Nielsen et al., 2010). So far, accelerometers, however, have not been suitable for detecting and characterizing patterns of walking behavior in cattle with a sufficient accuracy. Detailed information about the duration of walking and standing phases, number and duration of strides, and distance walked is a prerequisite for increasing the sensitivity and specificity of accelerometers to detecting lameness (Flower et al., 2005). It was already concluded by Chapinal et al. (2011) that accelerometers seem to be a promising tool for lameness detection on farm, especially when attached to a leg.

The objective of this study was to develop and validate a novel algorithm to monitor locomotor behavior based on the output of a 3-dimensional accelerometer collected from loose-housed dairy cows compared with video analysis (gold standard). It was hypothesized that a novel algorithm of the RumiWatch pedometer device (ITIN+HOCH GmbH, Fütterungstechnik, Liestal, Switzerland, http://www.rumiwatch.ch/) can be developed that provides a moderate to high correlation of parameters of behavior of dairy cows in both upright and lying positions between the output data of the pedometers and the data derived from temporarily staggered video analysis.

\section{MATERIALS AND METHODS}

\section{RumiWatch Pedometer}

The hardware used in this study was the RumiWatch pedometer, with the dimensions of $55 \mathrm{~mm}$ (width) $\times$ $100 \mathrm{~mm}$ (length) $\times 30 \mathrm{~mm}($ depth $)$ and a total weight of $126 \mathrm{~g}$. It is attached to one of the hind limbs of a cow proximal to the fetlock joint by a Velcro fastener. It represents a noninvasive electronic sensor, continuously collecting data at 10 readings per second, including a 3-dimensional accelerometer. The raw data are continuously stored on the integrated micro SD Memory Card (Swissbit AG, Bronschhofen, Switzerland).

\section{Concept of Algorithm Development and Validation}

The basic concept of definitions underlying all stages of development of the novel algorithm (RumiWatch software, ITIN + HOCH GmbH) is depicted in Figure 1. The normal locomotor activity of the cow consists of either lying or being in an upright position. The latter includes either standing or walking. Walking was defined as the activity characterized by at least 3 consecutive limb movements (strides), allowing the cow to change its location in space either in forward or backward direction. Standing was defined as the activity of a cow in upright position when it did not walk. Specific definitions of locomotor activity are given in Table 1.

Detection of the lying and standing behavior was based on pedometer angle estimations. The walking algorithm extracted parameters from the 3-dimensional accelerometer measurements. Development of the current version (V0.7.3.6), as described and validated in

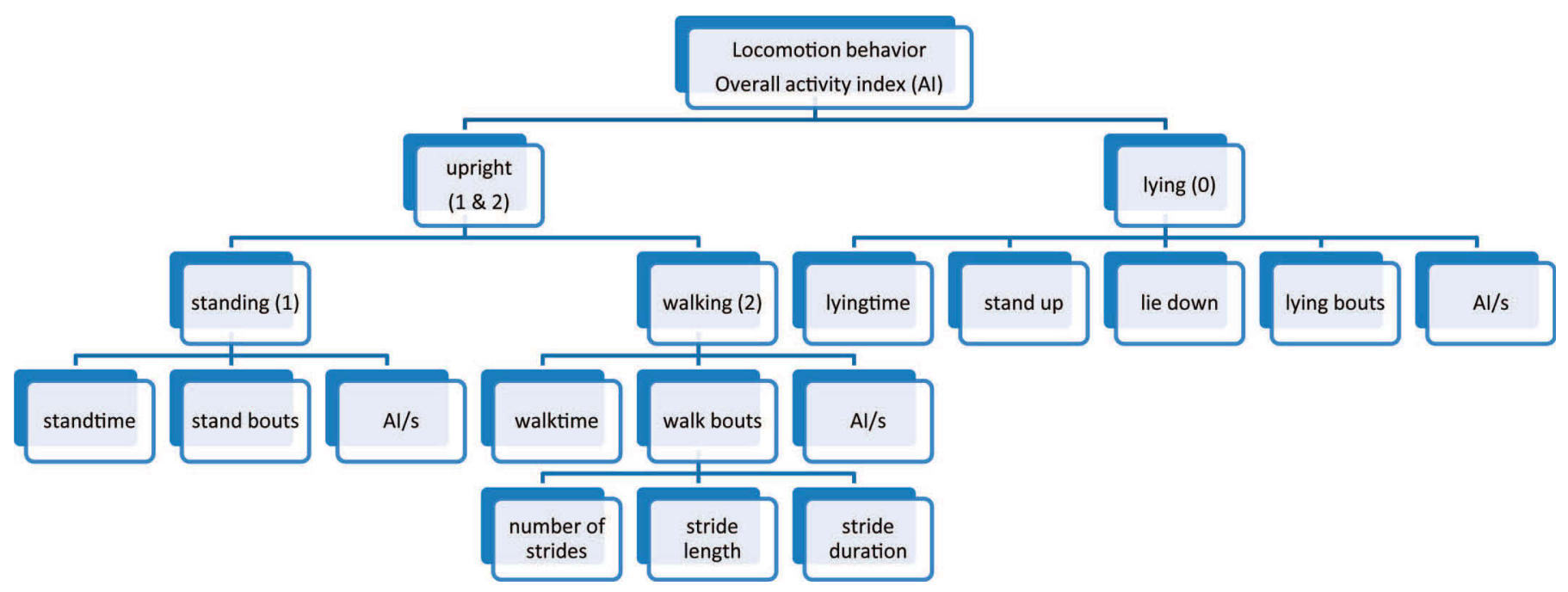

Figure 1. Classification tree of locomotion behavior of dairy cows used for the development of the novel RumiWatch (ITIN $+\mathrm{HOCH}$ GmbH, Fütterungstechnik, Liestal, Switzerland) algorithm. Color version available online. 
Table 1. Definitions of various variables used for quantifying locomotor activity of dairy cows

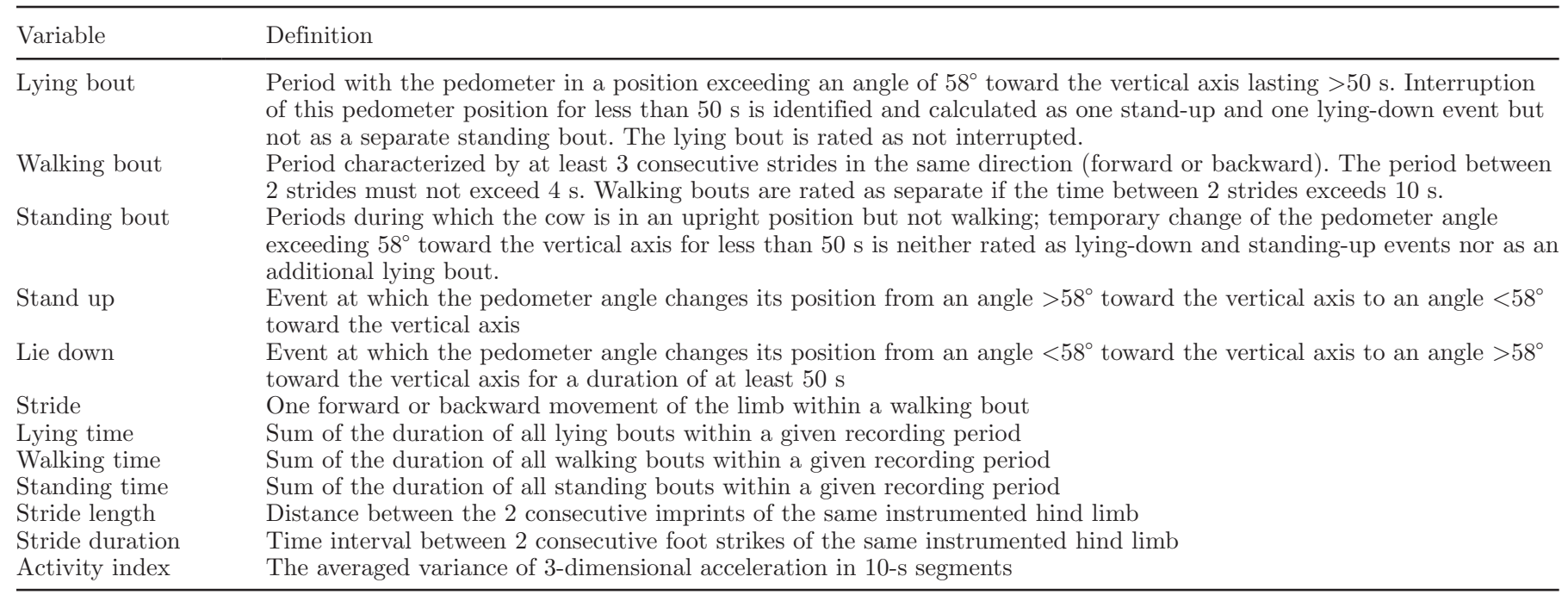

this paper, followed an empiric approach of several cycles of algorithm amelioration, validation. These cycles were repeated until the accuracy of detecting positionchange events and number of bouts (dichotomous data) exceeded $98 \%$ and the mean relative measurement error (RME) of continuous data describing locomotor activity was less than $20 \%$. The final version was validated using the $10-\mathrm{Hz}$ raw data collected from cows not included in the development of the algorithm.

\section{Animals and Experimental Procedures}

Development and validation of the algorithm were divided into 3 major experiments. They were carried out with the permission of the respective cantonal committee for animal experimentation.

Experiment 1. Experiment 1 was performed to elaborate the parameters lying time, stand up, lie down, and number of lying bouts (Table 1). The experiment was carried out at the experimental farm of Agroscope Research Station in Tänikon, Switzerland. The cows were kept in a loose housing system with straw-bedded cubicles. The walking and feeding alleys were made of plain concrete, and the outside paddock was covered with slatted concrete. The cows were milked 2 times a day and had free access to a TMR and a water trough. The cows were continuously videotaped over $24 \mathrm{~h}$ with 2 video recorders (Mobotix D14D-Sec and Mobotix M12D-Sec-DNight, Mobotix AG, Langmeil, Germany) mounted underneath the roof construction of the barn well above the cows. Time settings of the video recorders and pedometers were synchronized before the experiment on the computer used to initialize the devices. The cows were marked on the back and both flanks individually with colored numbers for un- equivocal identification. A total of 5 different versions of the algorithm were developed, using data of 30 cows. For validation of the final version, 18 cows (11 Brown Swiss; 6 Red Holstein; 1 Swiss Fleckvieh; median age: $4.1 \mathrm{yr}$, with range of 2.0 to $8.2 \mathrm{yr}$; median milk yield of $28 \mathrm{~kg} / \mathrm{d}$ ) were randomly selected from a pool of cows with a lameness score $(\leq 2)$ according to Sprecher et al. (1997). This revealed a pool of video data for validation of $432 \mathrm{~h}$.

Experiment 2. Experiment 2 was performed to elaborate 5 parameters describing behavior during upright position: standing time, walking time, number of standing bouts, number of walking bouts, and number of strides (Table 1). A hand-held digital video camera (Sony HDR-PJ740VE, Sony Corporation, Tokyo, Japan) was used to record the locomotion of the cows at 50 frames per second and to provide a posterior view of the hind legs while the respective cow was walking freely. The camera was initially synchronized by setting the clock of the video to match the time on the computer that was used to initialize each accelerometer. Each cow was videotaped for a period of $\geq 10 \mathrm{~min}$. A total of 8 versions of the algorithm were developed, using data of 20 cows kept under conditions similar to experiment 1. The version V0.7.3.6 was finally used to validate the accelerometer data of 21 cows (12 Brown Swiss; 9 Red Holstein; median age: $4.0 \mathrm{yr}$, with a range of 2.0 to 8.9 yr; median milk yield of $25.45 \mathrm{~kg} / \mathrm{d}$ ) videotaped over $\geq 10$ min, making up a total of 210 min of video data.

Experiment 3. Experiment 3 was performed to elaborate the parameters stride length $(\mathrm{m})$ and stride duration (s; Table 1). The cows were videotaped with a hand-held video recorder (Sony HDR-PJ740VE, Sony Corporation) from behind, when cows were walked by a handler for at least $5 \mathrm{~min}$. The walking distance was 
individually measured by using a distance-measuring wheel guided by the handler that was familiar with the cows. Two versions were developed using data of 20 cows kept under conditions similar to experiment 1 . The version V0.7.3.6 was finally used to validate the accelerometer data of 16 cows (16 Brown Swiss; median age of $3.1 \mathrm{yr}$, with range of 2.0 to $10.0 \mathrm{yr}$; median 305-d milk yield of $7,030.5 \mathrm{~kg}$ ) at Hürlimann-Grimm Ernst Farm in Ettenhausen, Switzerland.

\section{Data Analysis and Statistics}

For dichotomous data (stand up, lie down, lying bout, standing bout, and walking bout), the number of events or bouts detected by the RumiWatch algorithm was compared with the number of events detected in the video recordings (gold standard). The proportion of detected events and the respective $95 \%$ confidence interval were calculated. For continuous data, the RME was calculated as the deviation between accelerometer algorithm value and respective video recording using this formula: percent deviation $=(100 /$ video-recording observation) $\times$ absolute value (video-recording observation - RumiWatch observation). Mean and standard deviation were calculated to describe the RME for the different variables. A RME of $<1 \%$ was rated very low, 1 to $5 \%$ was rated low, and 6 to $20 \%$ was rated moderate. Agreement between continuous variables (time spent walking, standing, and lying; stride length; and stride duration) was expressed as correlation coefficients. The variables were not normally distributed; therefore, Spearman nonparametric correlation coefficient was used for the analyses. A correlation coefficient $\left(\mathbf{r}_{\mathrm{s}}\right)$ of $\mathrm{r}_{\mathrm{s}} \geq 0.9$ was rated as very high, $\mathrm{r}_{\mathrm{s}}=0.68$ to 1.0 as strong or high, $\mathrm{r}_{\mathrm{s}}=0.36$ to 0.67 as moderate, and $\mathrm{r}_{\mathrm{s}}$ $=\leq 0.35$ as weak correlation (Taylor, 1990). For continuous data, only one measurement for each cow was conducted; therefore, the degree of interdependence between RME and $r_{s}$ was not of any relevance. Furthermore, the variability between individual cows was not considered, as the comparison between accelerometer algorithm and respective video recording was done at cow level. All statistical analyses were undertaken using NCSS $^{9}$ (NCSS LLC, Kaysville, UT).

\section{RESULTS}

In experiment 1 , all the stand up $(\mathrm{n}=165)$ and lie down events $(\mathrm{n}=165)$ and all lying bouts $(\mathrm{n}=164)$ were correctly detected (Table 2). The estimate of lying time was perfect, with a mean measurement error of $0.09 \%$ and a very high correlation compared with the video recordings $\left(\mathrm{r}_{\mathrm{s}}=1\right.$; Table 3 ; Figure $\left.2 \mathrm{a}\right)$. In experiment 2 , all standing bouts were correctly detected (n $=132$ ) and only 1 out of 127 walking bouts was not detected by the algorithm (Table 2). Standing time per $10 \mathrm{~min}$ of recording time (mean $=7.18 \mathrm{~min}$; range 4.67-9.83) and walking time (mean $=2.82 \mathrm{~min}$; range $0.17-5.5$ ) were detected with a mean RME of 4.7 and $17.1 \%$, respectively, and similarly very high correlations of $\mathrm{r}_{\mathrm{s}}=0.96$ for both parameters (Table 2, Figure $2 \mathrm{~b}, 2 \mathrm{c})$. The mean RME of the number of strides was $6.23 \%$, and a very high correlation of $\mathrm{r}_{\mathrm{s}}=0.98$ between algorithm output and video recordings was estimated (Table 3, Figure 2d). In experiment 3, the median number of strides per 5 min of recording time was 41 strides (range 17-124 strides). The mean RME of stride duration was moderate $(6.65 \%)$, with a strong correlation of $\mathrm{r}_{\mathrm{s}}=0.75$ (Table 3; Figure 2e). The mean RME for stride length was moderate $(11.92 \%)$, with a strong correlation of $r_{\mathrm{s}}=0.81$ (Table 3, Figure 2f).

\section{DISCUSSION}

To the best of the authors' knowledge, this is the first description of a pedometer software allowing the detection of a variety of characteristics of cow walking behavior, correlating at a strong to mostly very high degree with the gold standard. The differentiation between lying position and being in an upright position of loose-housed cows and calves has already been possible with a high accuracy, using data loggers available

Table 2. Number and proportion of stand ups, lie downs, lying bouts, standing bouts, and walking bouts detected by the novel RumiWatch ${ }^{1}$ algorithm compared with the number observed by analyzing the video recordings (gold standard)

\begin{tabular}{|c|c|c|c|c|c|c|}
\hline \multirow[b]{2}{*}{ Experiment } & \multirow[b]{2}{*}{ Variable } & \multirow{2}{*}{$\begin{array}{l}\mathrm{VVR}^{2} \\
\text { (no.) }\end{array}$} & \multirow{2}{*}{$\begin{array}{l}\text { RumiWatch } \\
\text { algorithm (no.) }\end{array}$} & \multirow{2}{*}{$\begin{array}{l}\text { Proportion } \\
\text { detected }(\mathrm{p})\end{array}$} & \multicolumn{2}{|c|}{$95 \%$ CI of $p$} \\
\hline & & & & & Lower & Upper \\
\hline 1 & Stand up & 165 & 165 & 1.000 & 0.978 & 1.000 \\
\hline 1 & Lie down & 165 & 165 & 1.000 & 0.978 & 1.000 \\
\hline 1 & Lying bout & 164 & 164 & 1.000 & 0.978 & 1.000 \\
\hline 2 & Standing bout & 132 & 132 & 1.000 & 0.972 & 1.000 \\
\hline 2 & Walking bout & 127 & 126 & 0.992 & 0.957 & 0.999 \\
\hline
\end{tabular}

${ }^{1}$ ITIN+HOCH GmbH, Fütterungstechnik, Liestal, Switzerland.

${ }^{2} \mathrm{VVR}=$ visual video recording. 
Table 3. Relative measurement error (RME) of the variables lying time, standing time, walking time, number of strides, stride duration, and stride length given by the novel RumiWatch ${ }^{1}$ algorithm as compared with the result of video recording analysis (gold standard)

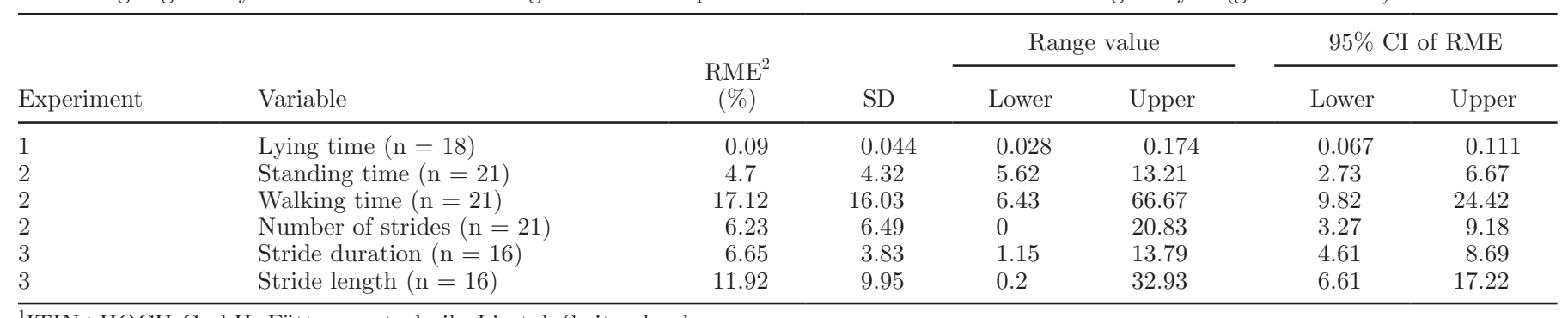

${ }^{1}$ ITIN+HOCH GmbH, Fütterungstechnik, Liestal, Switzerland.

${ }^{2}$ Mean relative measurement error between video recording and algorithm.

on the market (O'Driscoll et al., 2008; Trenel et al., 2009; Robert et al., 2009). With the novel algorithm, developed in this study, all lying and standing events, without exception, were correctly detected. To minimize the chance of misclassifying the grooming behavior of the hind limb with the cow standing as a lying down event, the duration at which the pedometer remains in horizontal position must exceed $50 \mathrm{~s}$ to detect a true lying down event with a consecutive lying bout. Similarly, to minimize the chance of misclassifying the short upright position in the course of a position change at lying as a short standing bout, the duration at which the pedometer remains in vertical position must exceed $50 \mathrm{~s}$ to detect a true standing bout.

As mentioned in many studies, the accuracy of correctly describing the walking behavior with the available data loggers was moderate to low (Robert et al., 2009; Trenel et al., 2009). Mattachini et al. (2013) reported that just 30\% of the walking events were correctly detected. This is mainly because the transition from standing to walking and vice versa is physically less distinctive than from the lying to the upright position (Trenel et al., 2009). Furthermore, the character and extent of limb movements with the cow standing but not walking is extremely variable, reaching from a simple and very short relief of the weight bearing of the limb, over frequent weight shifting from one limb to the contralateral limb in case both limbs are affected, to an obvious flexion of the limb lasting for several seconds. Definition of a step as opposed to a stride (defined here as being a limb movement within a walking phase) is, therefore, an extremely difficult task with a low detection rate. Even classification of individual limb movements at manual observation by professionals is not conclusive (Cutler, 2012). Hence, during the development of the current algorithm, it was decided to characterize the limb movements with the cow in upright position first by the walking behavior (walking phases, number of strides, stride duration, and stride length) and second by the activity index at standing and walking separately. The activity index (Table 1 ) represents the averaged variance of 3-dimensional acceleration in 10-s segments. Validation of the activity index by manually comparing video sequences of the cow with the output of the pedometer is not possible.

In a recent paper, describing the development of new algorithms for detection of walking behavior, it was shown that applying the rule that a walking phase must at least last $5 \mathrm{~s}$ optimized the classification rate (Nielsen et al., 2010). Combining this rule with the step-count detection at walking versus standing based on a moving average of $3 \mathrm{~s}$, the optimal misclassification rate was reduced to $10 \%$ (Nielsen et al., 2010). In the current study, walking phases were not defined by a minimal duration but rather by the condition that a walking phase must consist of at least 3 consecutive strides and the period between 2 strides must last less than $4 \mathrm{~s}$. A walking phase was rated as separate from the previous walking phase if the interval between 2 strides exceeded $10 \mathrm{~s}$. This allowed that only 1 out of 127 walking phases were not detected correctly and the correlation between automated and manual detection of the number of strides was $r_{s}=0.98$. The RME of walking time was quite high $(17.2 \%)$ as compared with other locomotor parameters described in this study. The reason for this high relative error might be the 10-s temporal quantization resolution of the shorter absolute walking time compared with the much longer standing or lying times.

Estimating the stride length and the stride duration represents a further important parameter of cow locomotor activity. Platz et al. (2008) showed an increase in stride length of cows kept on rubber compared with concrete floors. Flower et al. (2005) showed that lame cows have longer stride duration and shorter stride length compared with healthy cows using kinematic gait analysis. With the current algorithm, correlations of stride length and stride duration with the gold standards were both strong. 
a)
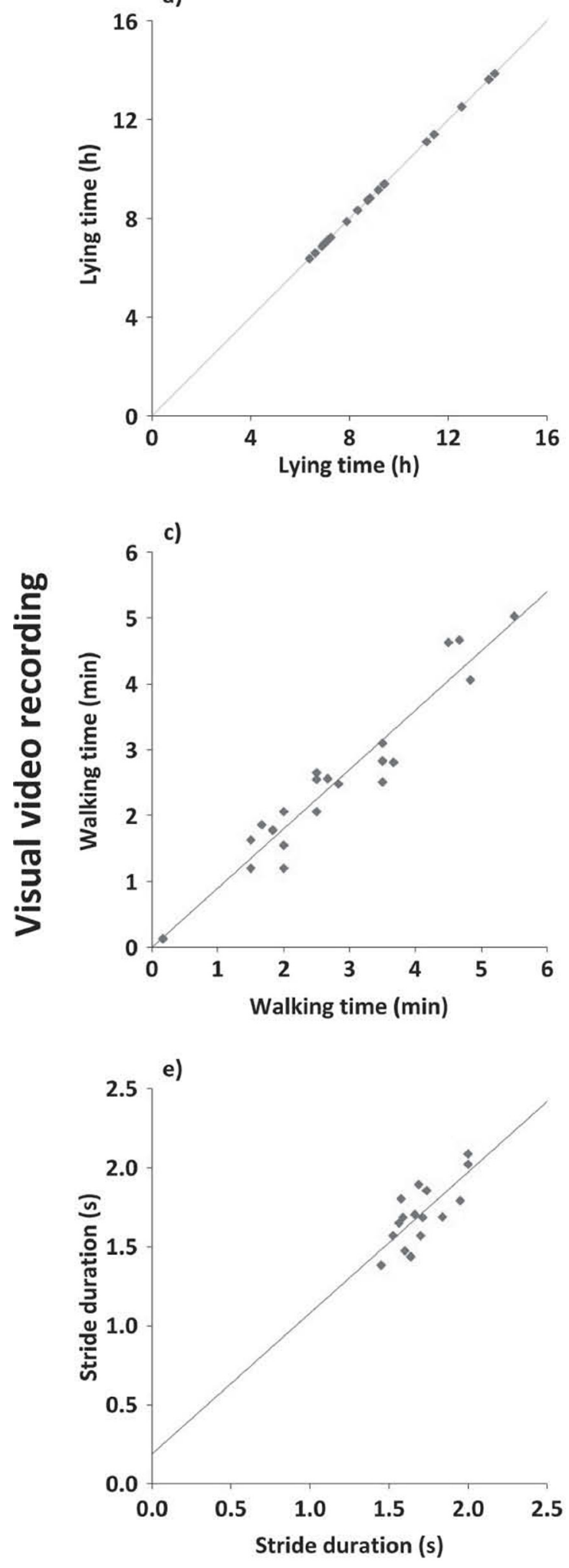

b)

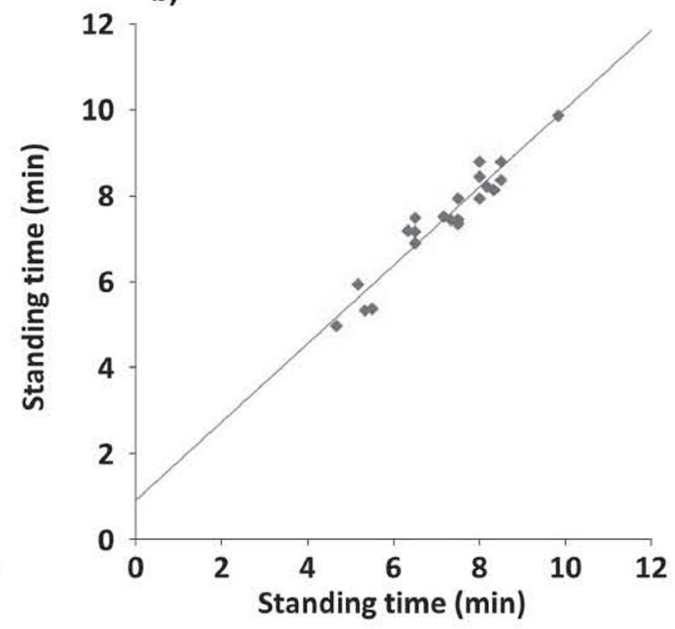

d)
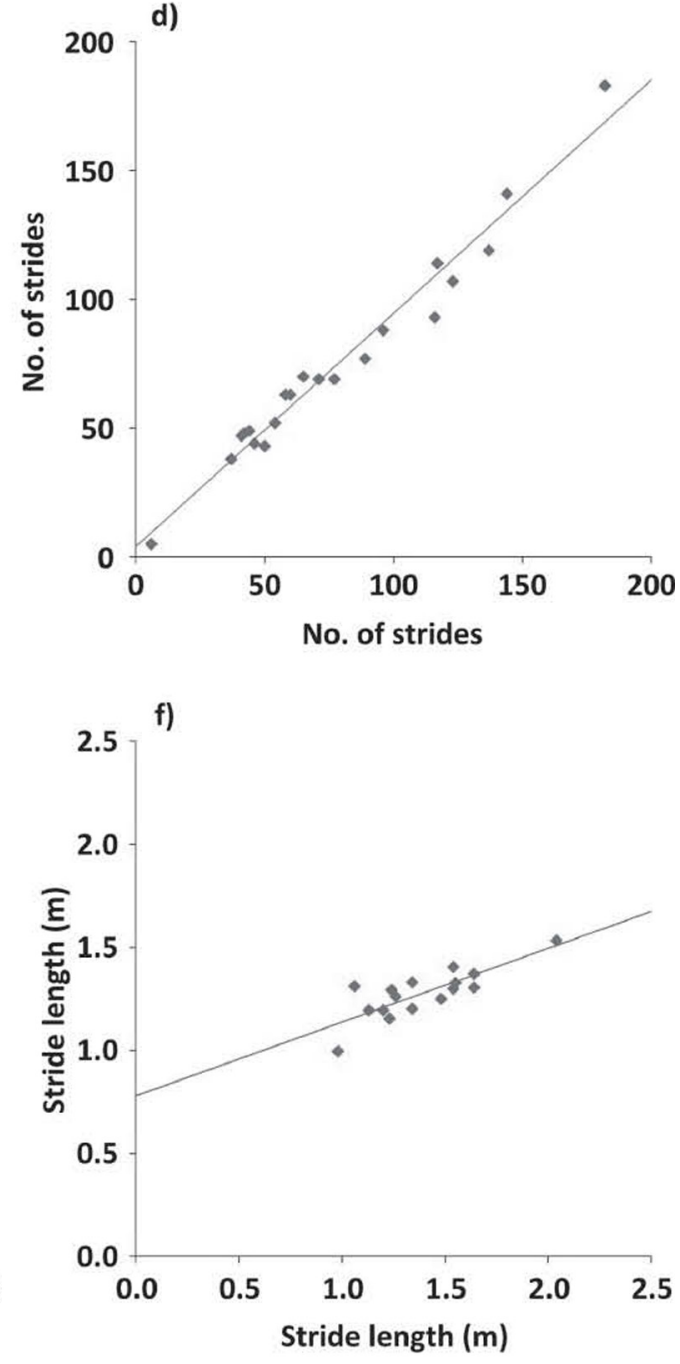

RumiWatch algorithm

Figure 2. Correlations between the RumiWatch (ITIN+HOCH GmbH, Fütterungstechnik, Liestal, Switzerland) algorithm output and the result of the manual video analysis (gold standard) of measurements of lying time (a), standing time (b), walking time (c), number of strides (d), stride duration (e), and stride length (f). 
The sampling rate of the RumiWatch pedometer was set at 10 samples per second, representing a very high rate. Mattachini et al. (2013) concluded that sampling intervals $\leq 2 \mathrm{~min}$ are required to accurately measure aspects of lying behavior such as number of lying bouts per day. From the results of the current study, it remains unclear whether reduction of the sampling rate to $1 \mathrm{~Hz}$ might be possible without loss of important information mainly concerning the walking behavior.

\section{CONCLUSIONS}

The results of this study suggest that the newly developed algorithm of the RumiWatch pedometer allows for the detection of several characteristics of the locomotor behavior of cows with a very high (lying time, standing time, walking time, and number of strides) or strong degree of correlation (stride duration and stride length). The proportion of correctly detected events exceeded $99 \%$ for the parameters number of lying bouts, standing bouts, walking bouts, stand up events, and lie down events, and the RME was less than $10 \%$ for the parameters lying time, standing time, number of strides, and stride duration as compared with manual observation. Using the new pedometer software, further research is warranted to study in more detail the normal locomotor behavior (focusing on walking) of healthy dairy cows and to evaluate the feasibility of the newly described parameters of cow walking for early detection of lameness.

\section{ACKNOWLEDGMENTS}

This study was generously supported by grants of the Fondation Sur-La-Croix (Basel, Switzerland) and the Swiss Federal Commission for Technology and Innovation CTI (Bern, Switzerland; grant No. 15234.2 PFLS-LS). We thank ITIN+HOCH GmbH, Liestal, Switzerland, for providing the RumiWatch pedometers for this project.

\section{REFERENCES}

Alsaaod, M., C. Romer, J. Kleinmanns, K. Hendriksen, S. Rose-Meierhofer, L. Plumer, and W. Buscher. 2012. Electronic detection of lameness in dairy cows through measuring pedometric activity and lying behavior. Appl. Anim. Behav. Sci. 142:134-141.

Chapinal, N., A. M. de Passille, M. Pastell, L. Hanninen, L. Munksgaard, and J. Rushen. 2011. Measurement of acceleration while walking as an automated method for gait assessment in dairy cattle. J. Dairy Sci. 94:2895-2901.

Cook, N. B., T. B. Bennett, and K. V. Nordlund. 2005. Monitoring indices of cow comfort in free-stall-housed dairy herds. J. Dairy Sci. 88:3876-3885

Cutler, J. 2012. Welfare in dairy cattle: Epidemiologic approaches for detection and treatment of lameness. $\mathrm{PhD}$ Thesis in Population Medicine. Univ. Guelph, Ontario, Canada.
Espejo, L. A., M. I. Endres, and J. A. Salfer. 2006. Prevalence of lameness in high-producing Holstein cows housed in freestall barns in Minnesota. J. Dairy Sci. 89:3052-3058.

Flower, F. C., D. J. Sanderson, and D. M. Weary. 2005. Hoof pathologies influence kinematic measures of dairy cow gait. J. Dairy Sci. 88:3166-3173.

Flower, F. C., and D. M. Weary. 2006. Effect of hoof pathologies on subjective assessments of dairy cow gait. J. Dairy Sci. 89:139-146.

Gonzalez, L. A., B. J. Tolkamp, M. P. Coffey, A. Ferret, and I. Kyriazakis. 2008. Changes in feeding behavior as possible indicators for the automatic monitoring of health disorders in dairy cows. J. Dairy Sci. 91:1017-1028.

Hudson, C., H. Whay, and J. Huxley. 2008. Recognition and management of pain in cattle. In Practice 30:126-134.

Ito, K., M. A. von Keyserlingk, S. J. Leblanc, and D. M. Weary. 2010. Lying behavior as an indicator of lameness in dairy cows. J. Dairy Sci. 93:3553-3560

Mattachini, G., E. Riva, C. Bisaglia, J. C. A. M. Pompe, and G. Provolo. 2013. Methodology for quantifying the behavioral activity of dairy cows in freestall barns. J. Anim. Sci. 91:4899-4907.

Muller, R., and L. Schrader. 2005. Individual consistency of dairy cows' activity in their home pen. J. Dairy Sci. 88:171-175.

Munksgaard, L., C. G. Reenen, and R. Boyce. 2006. Automatic monitoring of lying, standing and walking behavior in dairy cattle. J. Anim. Sci. 84:304.

Nielsen, L. R., A. R. Pedersen, M. S. Herskin, and L. Munksgaard 2010. Quantifying walking and standing behaviour of dairy cows using a moving average based on output from an accelerometer. Appl. Anim. Behav. Sci. 127:12-19.

Nordlund, K. V., N. B. Cook, and G. R. Oetzel. 2004. Investigation strategies for laminitis in problem herds. J. Dairy Sci. 87(E. Suppl.):E27-E35.

O'Callaghan, K. A., P. J. Cripps, D. Y. Downham, and R. D. Murray 2003. Subjective and objective assessment of pain and discomfort due to lameness in dairy cattle. Anim. Welf. 12:605-610.

O'Driscoll, K., L. Boyle, and A. Hanlon. 2008. A brief note on the validation of a system for recording lying behaviour in dairy cows. Appl. Anim. Behav. Sci. 111:195-200.

Platz, S., F. Ahrens, J. Bendel, H. H. Meyer, and M. H. Erhard. 2008 What happens with cow behavior when replacing concrete slatted floor by rubber coating: A case study. J. Dairy Sci. 91:999-1004.

Robert, B., B. J. White, D. G. Renter, and R. L. Larson. 2009. Evaluation of three-dimensional accelerometers to monitor and classify behavior patterns in cattle. Comput. Electron. Agric. 67:80-84.

Shearer, J. K., M. L. Stock, S. R. Van Amstel, and J. F. Coetzee. 2013. Assessment and management of pain associated with lameness in cattle. Vet. Clin. North Am. Food Anim. Pract. 29:135-156.

Sprecher, D. J., D. E. Hostetler, and J. B. Kaneene. 1997. A lameness scoring system that uses posture and gait to predict dairy cattle reproductive performance. Theriogenology 47:1179-1187.

Taylor, T. 1990. Interpretation of the correlation coefficient: a basic review. J. Diagn. Med. Sonogr. 1:35-39.

Trenel, P., M. B. Jensen, E. L. Decker, and F. Skjoth. 2009. Technical note: Quantifying and characterizing behavior in dairy calves using the IceTag automatic recording device. J. Dairy Sci. 92:33973401.

Urton, G., M. A. G. von Keyserlingk, and D. M. Weary. 2005. Feeding behavior identifies dairy cows at risk for metritis. J. Dairy Sci. 88:2843-2849.

Viazzi, S., C. Bahr, A. Schlageter-Tello, T. Van Hertem, C. E. Romanini, A. Pluk, I. Halachmi, C. Lokhorst, and D. Berckmans. 2013. Analysis of individual classification of lameness using automatic measurement of back posture in dairy cattle. J. Dairy Sci. 96:257-266.

Whay, H. R., D. C. J. Main, L. E. Green, and A. J. F. Webster. 2003 Assessment of the welfare of dairy cattle using animal-based measurements: Direct observations and investigation of farm records. Vet. Rec. 153:197-202.

Yunta, C., I. Guasch, and A. Bach. 2012. Short communication: lying behavior of lactating dairy cows is influenced by lameness especially around feeding time. J. Dairy Sci. 95:6546-6549. 